\title{
Caminhos trilhados e contribuiçóes para o desenvolvimento da terapia ocupacional no Brasil
}

\author{
Maria Luísa Guillaumon Emmel \\ Universidade Federal de São Carlos - UFSCar, São Carlos, SP, Brasil.
}

\begin{abstract}
Resumo: Este ensaio reflete os caminhos trilhados por mim na Terapia Ocupacional durante os mais de 40 anos de profissão, apresentando sinteticamente as iniciativas e as participações mais relevantes de minha carreira. Nele, é possível visualizar o percurso seguido para as escolhas dos temas de pesquisa e o início de uma série de projetos e de direcionamentos dados para impulsionar o crescimento e o reconhecimento da Terapia Ocupacional brasileira. A atuação com órgãos de financiamento e o fortalecimento das atividades de pesquisa foram sinalizados. Reconta-se ainda a história da criação do curso de Terapia Ocupacional da Universidade Federal de São Carlos (UFSCar), bem como do primeiro laboratório de pesquisa em Terapia Ocupacional do Brasil, da revista Cadernos de Terapia Ocupacional da UFSCar e do Programa de Pós-graduação em Terapia Ocupacional da UFSCar. Estão ainda registrados alguns dos principais desafios enfrentados no ensino, na extensão, na administração universitária e na produção de conhecimento na área, que contribuíram para o desenvolvimento da profissão.
\end{abstract}

Palavras-chave: Terapia Ocupacional, Educação Superior, Universidades.

\section{Tracked ways and contributions for the development of occupational therapy in Brazil}

\begin{abstract}
This essay reflects the paths I have taken in occupational therapy in more than 40 years in this profession, presenting briefly the main important activities and participation of my career. It is possible to visualize the route followed in the choices of research issues and the beginning of a series of projects and directions to growth and recognition of the Brazilian occupational therapy. The participation with the research funding grants and the strengthening of research activities are presented. Recounts the history of the foundation of the Occupational Therapy Program at Universidade Federal de São Carlos (UFSCar), the first research laboratory in Occupational Therapy in Brazil, the Journal of Occupational Therapy - UFSCar and also the Postgraduate Program in Occupational Therapy UFSCar (PPGTO). Some of the main challenges faced in teaching, community activities, the university management and the production of knowledge in occupational therapy are still registered, which contributed to the development of the profession.
\end{abstract}

Keywords: Occupational Therapy, Higher Education, Universities. Autor para correspondência: Maria Luísa Guillaumon Emmel, Departamento de Terapia Ocupacional, Universidade Federal de São Carlos,
Rodovia Washington Luís, Km 235, SP-310, CEP 13565-905, São Carlos, SP, Brasil, e-mail: maluemmel@gmail.com

Recebido em Abr. 30, 2016; 1ª Revisão em Jul. 1, 2016; Aceito em Set. 3, 2016. 


\section{O Começo de Tudo}

O motivo da minha escolha pela Terapia Ocupacional foi semelhante ao de muitos colegas que, no final da adolescência, não tinham bem clara a profissão que iriam escolher. Eu queria ajudar as pessoas, fazer a diferença em suas vidas, e, nessa busca, deparei-me com a descrição da profissão Terapia Ocupacional no livro do CESCEM - sistema vestibular da área Biológica em São Paulo, criado em 1964 -, o que me interessou porque parecia atender às minhas expectativas de vida profissional e pessoal. Era o primeiro ano que a Terapia Ocupacional participava de um vestibular integrado. Fui aprovada na Universidade de São Paulo (USP) e, em 1971, impus-me o desafio de conhecer a profissão que me faria estar aqui, agora, contando sobre a minha trajetória profissional.

O curso funcionava no quinto andar da Faculdade de Medicina da USP, na Avenida Dr. Arnaldo, em Sáo Paulo, e os revezes faziam parte de nosso cotidiano: queríamos saber mais sobre a profissão, mas não havia um suporte teórico-metodológico consistente, o que levava os alunos a constantes crises de identidade profissional.

Na busca por compreender a função da profissão, visitei, já no primeiro ano, locais onde trabalhavam terapeutas ocupacionais, mas não conseguia obter explicaçóes sobre o que fundamentava a Terapia Ocupacional: pareciam oferecer atividades a esmo, sem preocupação com o sentido que elas faziam para as pessoas, e essa foi uma das primeiras crises que vivi dentro do curso.

No segundo ano, iniciei estágios voluntários na Associação de Assistência à Criança Defeituosa (AACD) de São Paulo, instituição especializada em reabilitação de crianças com paralisia cerebral e transtornos do desenvolvimento. Foi ali que comecei a compreender o desenvolvimento infantil, a ver sentido nas atividades que eram ministradas às crianças e a raciocinar de maneira mais próxima de uma profissional de Terapia Ocupacional. Eu passava uma parte da tarde na biblioteca da própria $\mathrm{AACD}$, pesquisando sobre os casos que eu estava atendendo, e isso permitiu que eu fosse adquirindo maior segurança e domínio sobre minha atuação naquele espaço.

No terceiro e último ano do curso, os estágios profissionalizantes mostraram um leque maior de atuação nessa profissão. Depois de estagiar em uma escola especial, clínica psiquiátrica e centro de reabilitação neurológica, meu último estágio aconteceu em uma clínica de crianças com múltiplas deficiências, na qual permaneci trabalhando após minha formatura, em 1973. Wanira Scilla, a proprietária, foi uma supervisora extraordinária, que me ajudou a observar o que era de fato relevante e a amadurecer profissionalmente. Durante uma parte do ano de 1975, atuei também na Sociedade Pestalozzi de São Paulo, onde realizava atendimentos para o desenvolvimento de habilidades cognitivas e sociais em adolescentes.

Ainda enquanto estava no último ano de Terapia Ocupacional, matriculei-me no curso de Licenciatura da USP, no período noturno. Nascida e criada em uma família com muitos professores, neguei inicialmente essa possibilidade, mas, já na graduação, a docência começou a me atrair. No entanto, quando faltavam apenas duas disciplinas para terminar essa formação - que se constituíam nos estágios em salas de aula -, fui comunicada pelo coordenador que eu não poderia cursá-las, pois a formação de licenciada não era autorizada pelo Ministério da Educação (MEC) para a Terapia Ocupacional nem para os demais cursos da área de Saúde. Assim, interrompi aquele sonho apenas com um atestado das disciplinas que cursei.

\section{Novos Desafios em São Carlos}

Em janeiro de 1977, mudei-me para Sáo Carlos com meu primeiro filho, de um ano e meio, e o segundo de meus três filhos, com apenas 15 dias.

A Associação de Pais e Amigos dos Excepcionais (APAE) era uma das poucas instituiçôes de reabilitação na cidade, e fui contratada por ela no início de 1977. Tinha ali a função de orientar os professores, mas também atendi muitos casos.

\section{Pós-graduação}

Vários docentes do Programa de Pós-graduação em Educação Especial (PPGEEs) da Universidade Federal de São Carlos (UFSCar) desenvolviam pesquisas na APAE. Conversando com eles, interessei-me pelo programa, pois via na pós-graduação stricto sensu a possibilidade de melhor fundamentar minha prática, ampliar meus conhecimentos, desvendar o mundo da pesquisa e preparar-me para a carreira acadêmica, que me atraía. Ingressei em 1979 naquele programa, época em que quase nenhum terapeuta ocupacional brasileiro fazia pós-graduação stricto sensu.

Fazer pós em outra área impunha uma série de desafios: aprender outra linguagem, no caso a da área em questão; aprender a fazer pesquisa, uma vez que nossa formação não incluía nada a esse respeito; 
desenvolver pesquisa em Educação Especial e, para que a aprendizagem fosse significativa, era necessário "fazer a ponte" entre os novos conhecimentos obtidos e a Terapia Ocupacional. Busquei, então, para a minha pesquisa, um tema que aproximava as duas áreas, Educação Especial e Terapia Ocupacional. Eu já havia atendido muitas crianças com Síndrome de Down e sabia das dificuldades de comunicaçáo verbal dessa população. Atraída pelos estudos de Spitz (1980) sobre a interação entre mãe e filho, desenvolvi um estudo comparativo, buscando compreender melhor como ocorria a interação não verbal entre mães e seus filhos com e sem Síndrome de Down (EMMEL, 1985). O passo seguinte viria com o doutorado, cujo tema foi motivado por minhas atividades na clínica da UFSCar - futura Unidade Especial Núcleo de Atenção e Pesquisa em Saúde (UENAPES) e atual Unidade Saúde-Escola (USE) -, onde oferecia disciplinas práticas e supervisionava os estágios com crianças e adolescentes. Em meu projeto de doutorado, investiguei como ocorriam as interações sociais de crianças entre 7 e 9 anos durante brincadeiras em grupos (EMMEL, 1990).

\section{Nascimento do Curso de Graduação em Terapia Ocupacional da UFSCar}

Nos primeiros meses de 1978, surpreendi-me com a notícia de que o curso de graduação em Terapia Ocupacional estava sendo implantado na UFSCar - havia recebido autorização de funcionamento em abril de 1977 -, pelo Prof. Dr. José Rodrigues Louzâ, médico, docente do curso de Terapia Ocupacional da USP, meu ex-professor. Tomando conhecimento de que eu estava morando em Sáo Carlos, convidou-me para ministrar uma aula para a primeira turma de alunos que ingressaram no curso em agosto de 1978. Eu era, até aquele momento, a primeira terapeuta ocupacional com quem os alunos estavam tendo contato. Em março de 1979, fui contratada como docente da UFSCar, com o semestre já iniciado. Nos primeiros semestres, assumi todas as disciplinas específicas do curso (Fundamentos de Terapia Ocupacional, Terapia Ocupacional Geral, Atividades Terapêuticas), até que pudesse dividir com os novos colegas essa responsabilidade.

Muita coisa estava se transformando em minha vida: além do início da docência na UFSCar, eu havia acabado de ingressar no PPGEE e aguardava a chegada de minha filha para maio do mesmo ano.

$\mathrm{Na}$ medida em que eu assumia os encargos do novo curso, o Prof. Louzã, que até então assumira todas as responsabilidades da implantação do curso, espaçava suas vindas a São Carlos até passar, em agosto de 1979, os encargos da coordenaçáo e da montagem do curso para o meu gerenciamento.

Analisando o perfil do curso inicialmente oferecido, constatei que tinha a duração de três anos e oferecia uma formação voltada para o modelo médico. Enfrentei, então, meu primeiro desafio de reforma curricular, e conseguimos implantar, ainda para a primeira turma, que já se encontrava em curso, um programa de quatro anos, com um rol de disciplinas específicas de Terapia Ocupacional desde o início do curso, inclusão de disciplinas da área de Ciências Humanas e aumento da carga horária dos estágios (aprovada pelo Conselho de Ensino e Pesquisa da UFSCar em 9 de novembro de 1979).

São Carlos ainda não tinha nenhuma estrutura de atendimentos para o curso de Terapia Ocupacional fixar-se e formar seus profissionais. Assim, foi necessário preparar os espaços da cidade para a atuação prática dos alunos. Com algumas poucas colegas que haviam recém-ingressado como docentes, iniciamos com as instituições já existentes na cidade, com a proposta de oferecermos um serviço de Terapia Ocupacional naqueles locais. Na Santa Casa de Misericórdia de Sáo Carlos, tivemos o trabalho adicional da construção de um setor, o que envolveu todo o planejamento físico de estrutura, equipamentos e materiais.

O desconhecimento da Terapia Ocupacional pela comunidade de São Carlos e também pelos profissionais de saúde local foi outro problema, enfrentado com a implantação de um projeto de sensibilização e de esclarecimento sobre essa profissão na cidade e região. Envolveu contatos pessoais com profissionais, discussóes de casos com médicos da cidade e ciclos de palestras abertos a toda a população, que foram os disparadores para a criação de um evento maior, que aglutinasse profissionais e alunos em torno dos assuntos da Terapia Ocupacional. Assim nasceu a I Semana de Terapia Ocupacional da UFSCar, em 1980, que organizei com os alunos das turmas de 1978 e 1979, e que se mantém até os dias de hoje.

A vida na universidade era muito intensa, e participei de atividades que ocorriam em vários de seus setores. Havia um "burburinho" que anunciava uma universidade em crescimento, e isso nos estimulava a fazer todas as reivindicaçóes que julgássemos necessárias para que ela se transformasse na melhor do país. Foi com esse espírito que me envolvi com tantas demandas, da Terapia Ocupacional e da universidade como um todo.

À medida que tornávamos conhecido o nosso curso e o trabalho da UFSCar, também passávamos a ser 
requisitadas para assessorarmos novas propostas de ensino de Terapia Ocupacional. Foi assim que integrei o grupo de consultores do Conselho Estadual de Educação, para emitir pareceres técnicos em relação às escolas superiores municipais, e a Comissão de Verificação do MEC/SESu, para autorização, credenciamento e recredenciamento de cursos e instituições, onde também participei da Comissão de Especialistas de Ensino de Fisioterapia e Terapia Ocupacional, para analisar processos de autorizaçáo de novos cursos de graduação.

Participei também de trabalhos com outras instituições de ensino para auxiliar nos projetos pedagógicos dos cursos. Destaco ainda a consultoria ad hoc que até hoje mantenho com a Coordenaçáo de Aperfeiçoamento de Pessoal de Nível Superior (CAPES), Fundação de Amparo à Pesquisa do Estado de Sáo Paulo (FAPESP), Conselho Nacional de Desenvolvimento Científico e Tecnológico (CNPq), Pró-Reitoria de Pesquisa da UFSCar - PIBIC/PIBITI.

\section{Atividades de Ensino de Graduação}

Ensinar Terapia Ocupacional para futuros profissionais na área era um desafio significativo na década de 1970. Isso porque o curso de graduação em Terapia Ocupacional da UFSCar foi um dos primeiros, no Brasil, a estruturar um currículo de quatro anos de duração, com disciplinas específicas em praticamente todos os semestres. A produção científica no país era quase nula, e o acesso à literatura estrangeira, bastante limitado. Os profissionais da área não tinham a tradição de escrever e divulgar seus conhecimentos, e isso dificultava ainda mais a busca por referenciais teóricos nacionais, o que comprometia também a formação do profissional.

Com essas dificuldades todas, cabia a nós buscarmos meios de pesquisar e de produzir conteúdos que se adequassem à formaçáo de nossos alunos, com fundamentaçáo sustentada para a prática desse profissional, o que busquei sempre fazer em minhas aulas nas disciplinas: Fundamentos de Terapia Ocupacional, Terapia Ocupacional Aplicada à Infância e Adolescência, Análise de Atividades, Técnicas de Observação, Estágios de Observação, Estágios Profissionalizantes, Unidade Educacional de Recursos e Atividades em Terapia Ocupacional, Unidade Educacional de Pesquisa em Terapia Ocupacional e Grupo de Reflexões da Prática.

\section{Envolvimento com o Ensino e a Orientação na Pós-graduação}

Minhas primeiras experiências como docente da Pós-graduação foram no Programa de Pós-graduação em Educação Especial (PPGEE) da UFSCar, onde fui credenciada em 1992, passando a orientar vários trabalhos de mestrado e de doutorado de terapeutas ocupacionais e de outros profissionais.

No início dos anos de 2000, fui credenciada pelo Programa de Pós-graduação em Educação da Universidade de Sorocaba (UNISO) e lá orientei alunos de mestrado.

Em 2010, iniciamos o Programa de Pós-graduação em Terapia Ocupacional (PPGTO) na UFSCar, em nível de mestrado, a partir de um projeto estruturado por mim e pelas colegas Cláudia Maria Simões Martinez, Thelma Simóes Matsukura, Roseli Esquerdo Lopes e Ana Paula Serrata Malfitano. Nesse programa, novamente o desafio era construir conteúdos para a pós-graduação. No entanto, já foi possível não só utilizar referências de nossos colegas que publicavam em revistas nacionais, mas também foi bem mais fácil acessar periódicos internacionais, em razão da abertura das bases de dados pela internet (MALFITANO et al., 2013).

Em 2015, mais um projeto conjunto foi aprovado pela CAPES, e o PPGTO da UFSCar iniciou suas atividades de pós-graduação em nível de doutorado.

\section{Criação do Laboratório de Atividade e Desenvolvimento (LAD)}

Em 1990, após defender meu doutorado, já tinha reservado um pequeno espaço para pesquisas em meu gabinete do Departamento de Terapia Ocupacional. Nascia o primeiro laboratório de pesquisa em Terapia Ocupacional do Brasil dentro de uma universidade. Chamei-o Laboratório de Atividade e Desenvolvimento (LAD), e o projeto era que aquele fosse o embriāo de um espaço para o desenvolvimento de pesquisas da Terapia Ocupacional em torno das temáticas "atividade humana" e "desenvolvimento humano".

Várias colegas estavam chegando à universidade e algumas delas se juntaram àquela proposta: a Profa. Dra. Cláudia Maria Simóes Martinez, que desenvolvia seu mestrado com famílias, foi a primeira; em seguida, vieram a Profa. Dra. Thelma Simóes Matsukura, que atuava em Saúde Mental Infantil, e a Profa. Dra. Marina Palhares, que vinha de uma formação pós-graduada na área da Educação. 
Somado ao meu interesse pela ocupação humana, especialmente pelo papel do brinquedo e do brincar, nossas experiências alimentavam a constituiçáo de um grupo que compreendia a relação saúde-doença e o desenvolvimento da criança como interdependentes das experiências sociais, incluindo família, escola, condiçôes de educação e brinquedo.

Com esse pequeno grupo que tinha os mesmos objetivos, o laboratório cresceu e nucleou muitas pesquisas e trabalhos de extensão, abrindo novas frentes de investigação e também de atuação para o terapeuta ocupacional. Muitos alunos passaram pelo LAD para desenvolverem seus projetos de extensão, iniciação científica, mestrado e doutorado, além de projetos isolados como voluntários, dando uma dinâmica ao LAD que nos estimulava a fazer sempre mais.

\section{Os Caminhos da Pesquisa e a Produção e Divulgação de Conhecimento}

A necessidade da pesquisa em Terapia Ocupacional sempre esteve presente em minhas convicçôes. Como, até a década de 1970, não se tinha expectativas quanto à carreira docente, a formação de pós-graduação se limitava à especialização, o que dava maior sustentação à prática clínica em Terapia Ocupacional. Com o aumento do número de cursos de graduação no território nacional, a necessidade de docentes capacitados para ministrar disciplinas específicas tornou-se uma realidade, e, consequentemente, a formação em pós-graduação stricto sensu começou a ser buscada. Como não havia nenhum programa de Terapia Ocupacional no Brasil, alguns poucos profissionais iam para o exterior, onde já havia pós-graduação em Terapia Ocupacional, enquanto a maioria se inseria na pós-graduação em áreas afins, como a Educação e a Psicologia (EMMEL; LANCMAN, 1999, 2003).

As agências de fomento, por sua vez, eram impermeáveis não só a abrir financiamento para aqueles que não fossem doutores, mas também a Terapia Ocupacional era uma profissão desconhecida para elas. Em meados dos anos de 1980, o grupo de docentes da Terapia Ocupacional da UFSCar abriu conversaçóes com o CNPq para buscar sensibilizar aquele órgão para as questóes de nossa área. A resposta veio em forma de tarefa: fazer um levantamento nacional sobre a situação da Terapia Ocupacional. Juntamos, então, um pequeno grupo e reunimos esses dados, até montarmos o primeiro relatório, com o levantamento nacional da situação dos cursos e da capacitaçáo dos docentes terapeutas ocupacionais. Essas e outras ações que se seguiram a partir de grupos de docentes de diversas instituiçóes foram sensibilizando o CNPq para a presença de uma nova profissão a ser considerada (TOYODA; PINTO; EMMEL, 1986; TOYODA et al., 1988). Aos poucos fomos abrindo caminhos, técnicos e políticos, no CNPq e também na FAPESP. A massa crítica de demandas aumentou, e fazemos esse esforço até hoje.

Em todo o país, a Terapia Ocupacional mostrava que estava crescendo, e as oportunidades e os desafios estavam sempre aparecendo à nossa frente, mostrando-nos que era preciso ampliar o campo de atuaçáo do terapeuta ocupacional para as novas demandas da sociedade. Foi assim que, por várias vezes, abracei um novo tema de pesquisa, por entender que era de competência da Terapia Ocupacional, podendo abrir espaços de trabalho para este profissional.

Em 1989, criei e cadastrei no Diretório dos Grupos de Pesquisa do CNPq o grupo "Terapia Ocupacional: Processos do Desenvolvimento, Atividade Humana e Tecnologias em Saúde", que centra seus estudos no cotidiano e no fazer humano, nas várias fases do ciclo de vida e nos diferentes contextos, buscando compreender os processos de desenvolvimento ocupacional, de aquisição e recuperação de habilidades, e de desenvolvimento e aplicação de tecnologias de apoio. Em 1990, criei e cadastrei também o grupo "Formação e Capacitação em Terapia Ocupacional", que se propóe a investigar questôes relativas à formação do terapeuta ocupacional e suas implicaçôes na vida desse profissional.

A partir dos anos de 1980, foram os estudos de Kielhofner que me deram maior sustentação científica para a compreensão do papel da ocupação humana na vida e na saúde das pessoas (KIELHOFNER et al., 1980). Essas bases foram sendo fortalecidas com outros autores da Terapia Ocupacional, entre eles Yerxa (1993) e Wilcock (1993), e mais recentemente com a ciência ocupacional, que vem contribuindo para o conhecimento sobre a complexidade da ocupação humana (PIERCE, 2001; RUDMAN, 2013).

Tais bases teóricas e a compreensão mais aprofundada do homem enquanto ser ocupacional desfizeram para mim algumas limitaçôes da atuação e favoreceram a ampliaçáo do meu campo de ação, revelando-me novas possibilidades.

No final da década de 1990, nosso grupo de pesquisa foi chamado pela Faber-Castell, fábrica de produtos escolares, localizada na cidade de São 
Carlos, para analisarmos a adequação de materiais para o uso de crianças. Estávamos entrando em uma grande indústria para mostrar o que um terapeuta ocupacional pode fazer, abrindo novas frentes de trabalho para esse profissional, agora com pessoas sem deficiência. Especialmente em locais novos, que poderiam significar espaços de trabalho para a Terapia Ocupacional, entrávamos sempre com alunos como estagiários. Surgiram vários projetos dessa parceria que durou mais de quatro anos, e essa foi uma experiência incrível que nos proporcionou uma visão da pesquisa aplicada à produção.

A acessibilidade foi outro tema que abracei, e o primeiro projeto surgiu na disciplina Análise e Aplicação Terapêutica da Atividade. Em 1998, já bastante atenta à falta de acessibilidade no campus de São Carlos, optei por incluir esse conteúdo na disciplina, oferecendo aos alunos o desenvolvimento de alguns projetos de identificação de barreiras arquitetônicas no campus e também no centro da cidade de São Carlos como forma de fixação do conteúdo teórico ministrado em classe. Esse trabalho foi compilado em relatórios que entreguei à Reitoria e à Prefeitura de São Carlos. A Reitoria destinou recursos para iniciar as primeiras adequaçôes dentro da universidade, e essa iniciativa deu início a vários outros projetos sobre acessibilidade, que orientei e continuo orientando (EMMEL; CASTRO, 2003; EMMEL; GOMES; BAUAB, 2010; CRUZ; AGNELLI; EMMEL, 2012; GOMES; EMMEL, 2016).

Em 2000, meu grupo de trabalho e eu nos inserimos em outro grande projeto desenvolvido na EMBRAER. Nosso objetivo era analisar as condições da empresa para absorver funcionários com deficiências, além de avaliar a qualidade de vida dos funcionários daquela fábrica e propor soluçôes. Eu inseria, assim, esse novo tema de pesquisa em minha vida profissional (EMMEL et al., 2002; EMMEL, 2012).

Na EMBRAER, o que as pessoas faziam e o tempo despendido com as atividades de seu dia a dia davam mostras de influir diretamente em sua qualidade de vida. A partir de entáo, tenho aprofundado meus conhecimentos e desenvolvido pesquisas centradas na relação entre a ocupação e o uso do tempo (STINSON, 1999; EMMEL et al., 2002; FARNWORTH, 2003; ZEMKE, 2004; PEMBERTON; COX, 2011; NUNES et al., 2013; LOURENÇO; EMMEL, 2016).

\section{Criação do Periódico "Cadernos de Terapia Ocupacional da UFSCar"}

Como já mencionado, a história da Terapia Ocupacional brasileira foi marcada, durante muitos anos, pela falta de publicaçóes científicas. Isso obrigava os profissionais a se atualizarem em literatura estrangeira, mas que, embora bem fundamentada, não trazia estudos relacionados à realidade brasileira.

Foi nesse contexto que, em 1989, criamos um instrumento para canalizar a produção científica que começava a aparecer: os Cadernos de Terapia Ocupacional da UFSCar, que teve lançado seu primeiro número em 1990, comigo na direção dos trabalhos.

\section{Envolvimento com a}

\section{Administração Universitária}

Meu envolvimento com o curso de Terapia Ocupacional e com a UFSCar levou-me a assumir tarefas administrativas que eu não achava que fossem acontecer em minha vida de professora. A instalação do curso me colocou na coordenação dele. Mais tarde, entre 1985 e 1987, assumi a chefia do Departamento de Ciências da Saúde com a missão de conduzir um processo de departamentalizaçáo que criaria um Departamento de Fisioterapia e Terapia Ocupacional, separando-o da Enfermagem e da área básica da Saúde, o que se formalizou em 20 de fevereiro de 1986.

Entre 1991 e 1997, fui vice-diretora e, posteriormente, diretora do Centro de Ciências Biológica e da Saúde da UFSCar (CCBS), que congregava nove departamentos das áreas de Ciências Biológicas e de Ciências da Saúde. Durante esses dois mandatos, além de coordenar a instalação do novo curso de Educação Física na UFSCar, desenvolvemos ações para reestruturar e equipar os laboratórios de ensino e criar outros novos (para a Terapia Ocupacional, Fisioterapia e Educação Física). Participamos em dois grandes projetos institucionais: EXIMBANK e BID (do Banco Interamericano de Desenvolvimento), com o levantamento de demandas de equipamentos para essas duas áreas. Ainda, coordenamos o processo de distribuição de área física do Centro de Ciências Biológica e da Saúde, com a realocação dos departamentos da área da Saúde e a construção de mais de $8 \mathrm{mil} \mathrm{m}^{2}$ de área, e coordenamos o Projeto FAPLIVROS III do CCBS, que visava à recomposição 
e à atualizaçáo do acervo da Biblioteca Central da UFSCar nas áreas Biológica e da Saúde.

Entre 2004 e 2008, eu estava novamente envolvida com a universidade como um todo, assumindo a Pró-Reitoria de Extensão da UFSCar. O princípio da indissociabilidade entre ensino, pesquisa e extensão foi mantido e fortalecido, uma vez que essas três atividades se retroalimentam como partes de um todo, e náo como unidades separadas da vida acadêmica, potencializando a geração de saber colocado à disposição da sociedade e viabilizando açôes transformadoras. Entre as várias iniciativas desenvolvidas a partir desse lugar estấo os programas institucionais, dos quais destaco o Programa Qualidade de Vida na UFSCar, que teve como objetivo desenvolver açóes para a melhoria das condiçóes de vida dos servidores docentes e técnico-administrativos. Coordenei também, com o Escritório de Desenvolvimento Físico da UFSCar, a primeira edição do Programa Incluir MEC/SESu, entre 2005 e 2007, com uma proposta de eliminação de barreiras arquitetônicas nos campi, buscando minimizar as dificuldades de acessibilidade que havíamos constatado em trabalhos anteriores. Na área de Cultura, merecem destaque as gestôes realizadas para equipar e colocar em funcionamento o CineUFSCar e a Rádio UFSCar, propostas que se concretizaram nessa gestão.

Mantive também envolvimento com o Fórum de Pró-Reitores de Extensão das Universidades Públicas Brasileiras, no qual assumi, em 2005, a coordenação Sudeste da área de Cultura do Fórum e, em 2006, a vice-coordenadoria do Fórum da Regional Sudeste em todas as áreas.

\section{Encerrando um Ciclo}

A Terapia Ocupacional e a UFSCar compuseram e moldaram parte significativa de minha vida, e a elas me dediquei durante todos esses anos.

Sempre defendi a profissão que acredito, a universidade que acredito, e hoje consigo ver que as batalhas que travamos não foram em vão. Com meus colegas, abrimos caminhos e plantamos sementes de nossa profissão, lutando para a sua representatividade técnica e científica, que fortaleceram a pesquisa e a sistematização do conhecimento em Terapia Ocupacional, desenhando novos horizontes que agora alimentam o percurso dos atuais estudantes e profissionais.

Aposentada desde agosto de 2015, mantenho ainda uma contribuição ao PPGTO, com a orientação de alunos de doutorado e o desenvolvimento de pesquisas.
Vejo, com satisfação, vários de meus ex-alunos (de graduação e de pós-graduação) seguindo carreira acadêmica com brilhantismo, liderando equipes, desenvolvendo programas que vão melhorar a vida da população.

Ver esse movimento acontecendo me dá a certeza de que fizemos o que tinha de ser feito e a tranquilidade de afirmar que, se não acertamos em tudo, pelo menos boa parte do nosso trabalho foi recompensado.

\section{Referências}

CRUZ, D. M. C.; AGNELLI, L. B.; EMMEL, M. L. G. Adaptação ambiental. In: CRUZ, D. M. C. (Ed.). Terapia Ocupacional na reabilitação pós-acidente vascular encefálico: atividades de vida diária e interdisciplinariedade. São Paulo: Santos, 2012. p. 193-213.

EMMEL, M. L. G. Interação não verbal: um estudo comparativo entre díades com crianças normais e com Síndrome de Down. 1985. 154 f. Dissertação (Mestrado em Educação Especial) - Universidade Federal de São Carlos, São Carlos, 1985.

EMMEL, M. L. G. Competência social: a função da atividade. 1990. 265 f. Tese (Doutorado em Psicologia) Universidade de São Paulo, São Paulo, 1990.

EMMEL, M. L. G. Trabalho e qualidade de vida dos terapeutas ocupacionais: estudo de uma amostra brasileira. Cadernos de Terapia Ocupacional da UFSCar, São Carlos, v. 20, n. 1, p. 55-63, 2012.

EMMEL, M. L. G. et al. Qualidade de vida e promoção em saúde junto a trabalhadores: uma proposição de diagnóstico e intervenção em Terapia Ocupacional. Cadernos de Terapia Ocupacional da UFSCar, São Carlos, v. 10, n. 1, p. 30-41, 2002.

EMMEL, M. L. G.; CASTRO, C. B. Barreiras arquitetônicas no campus universitário: o caso da UFSCar. In: MARQUEZINE, M. C. et al. (Ed.). Educação fisisica, atividades motoras e lúdicas e acessibilidade de pessoas com necessidades especiais. Londrina: EDUEL, 2003. p. 177183.

EMMEL, M. L. G.; CRUZ, D. M. C.; FIGUEIREDO, M. O. An historical overview of the development of occupational therapy educational institutions in Brazil. South African Journal of Occupational Therapy, South African, v. 45, n. 2, p. 62-66, 2015.

EMMEL, M. L. G.; GOMES, G.; BAUAB, J. Universidade com acessibilidade: eliminando barreiras e promovendo a inclusão em uma universidade pública brasileira. Revista Brasileira de Ciências da Saúde, João Pessoa, v. 14, n. 1, p. 7-20, 2010.

EMMEL, M. L. G.; LANCMAN, S. Quem são nossos mestres e doutores? $\mathrm{O}$ avanço da capacitação docente em Terapia Ocupacional no Brasil. Cadernos de Terapia 
Ocupacional da UFSCar, São Carlos, v. 7, n. 1, p. 29-38, 1999.

EMMEL, M. L. G.; LANCMAN, S. La recherche en ergothérapie: développement de la formation des enseignants au Brésil. Canadian Journal of Occupational Therapy, Ottowa, v. 70, n. 2, p. 97-100, 2003.

FARNWORTH, L. Time use, tempo and temporality: occupational therapy's core business or someone else's business. Australian Occupational Therapy Journal, Austrália, v. 50, n. 3, p. 116-126, 2003.

GOMES, L.; EMMEL, M. L. G. Mapeamento da acessibilidade em edifícios públicos de cultura. Cadernos de Terapia Ocupacional da UFSCar, São Carlos, v. 24, n. 3, p. 519-530, 2016.

KIELHOFNER, G. et al. Model of human occupation: theory and application. Baltimore: Lippincott Williams \& Wilkins, 1980.

LOURENÇO, M. C.; EMMEL, M. L. G. O uso do tempo em uma população de adultos jovens universitários: um estudo exploratório. Revista Brasileira de Iniciação Científica, Itapetininga, v. 3, n. 3, p. 75-89, 2016.

MALFITANO, A. P. S. et al. Programa de Pós-graduação stricto sensu em Terapia Ocupacional: fortalecimento e expansão da produçáo de conhecimento na área. Revista Brasileira de Atividade Física \& Saúde, Pelotas, v. 18, n. 1, p. 105-111, 2013.

NUNES, F. B. S. et al. Retratos do cotidiano de meninos de cinco e seis anos: a atividade de brincar. Cadernos de Terapia Ocupacional da UFSCar, São Carlos, v. 21, n. 2, p. 275-287, 2013. http://dx.doi.org/10.4322/ cto.2013.029.

PEMBERTON, S.; COX, D. L. What happened to the time? The relationship of occupational therapy to time.
British Journal of Occupational Therapy, Inglaterra, v. 74, n. 2, p. 78-85, 2011.

PIERCE, D. Untangling occupation and activity. American Occupational Therapy Association, Boston, v. 55, n. 2, p. 138-146, 2001.

RUDMAN, D. L. Enacting the critical potential of occupational science: problematizing the individualizing of occupation'. Journal of Occupational Science, Australia, v. 20, n. 4, p. 1-16, 2013. http://dx.doi.org/10.1080/14 427591.2013 .803434 .

SPITZ, R. O primeiro ano de vida. São Paulo: Martins Fontes, 1980.

STINSON, L. L. Measuring how people spend their time: a time-use survey design. Monthly Labor Review, Washington, v. 122, n. 8, p. 12-19, 1999. Disponível em: <http://www.bls.gov/mlr/1999/08/art3full.pdf>. Acesso em: 2 maio 2016.

TOYODA, C. Y. et al. Programa básico de Terapia Ocupacional. São Carlos: [s.n.], 1988. Relatório CNPq (restrito).

TOYODA, C. Y.; PINTO, J. M.; EMMEL, M. L. G. Evoluçâo cientifica da Terapia Ocupacional no Brasil (1984-1986). São Carlos: [s.n.], 1986. Relatório CNPq (restrito).

WILCOCK, A. A theory of the human need for occupation. Journal of Occupational Science, Australia, v. 1, n. 1, p. 17-24, 1993.

YERXA, E. Occupational Science: a new source of power for participants in occupational therapy. Journal of Occupational Science, Australia, v. 1, n. 1, p. 3-10, 1993.

ZEMKE, R. Time, space, and the kaleidoscopes of occupation. American Journal of Occupational Therapy, Boston, v. 58, n. 6, p. 608-620, 2004.

\section{Notas}

${ }^{1}$ No Brasil, os terapeutas ocupacionais utilizavam o termo "atividade" em lugar de "ocupação". Não havia ainda a discussão sobre as diferenças entre "atividade" e "ocupação" que temos hoje e a exploração da abrangência desta última (PIERCE, 2001). Atualmente, no Brasil, o termo "ocupação" começa a ser mais difundido, porém "atividade" continua sendo o mais utilizado. O texto reflete um pouco esse momento de passagem, razão pela qual ambos são aqui ainda utilizados como sinônimos. 